\title{
Developmentally defined regulation of thyroid hormone metabolism by glucocorticoids in the rat
}

\author{
S Van der Geyten and V M Darras \\ Laboratory of Comparative Endocrinology, Zoological Institute, KU Leuven, Naamsestraat 61, B-3000 Leuven, Belgium \\ (Requests for offprints should be addressed to S Van der Geyten, Email: serge.vandergeyten@bio.kuleuven.ac.be)
}

\begin{abstract}
Glucocorticoids are known regulators of thyroid function in vertebrates. In birds they have clear tissue-specific and age-dependent effects on thyroid hormone metabolism. In mammals, however, few studies exist addressing these aspects using an in vivo model system. We therefore set out to examine the acute effects of a single dose of dexamethasone (DEX) on plasma 3,5,3'-tri-iodothyronine $\left(\mathrm{T}_{3}\right)$ and thyroxine $\left(\mathrm{T}_{4}\right)$ levels, as well as on the activity of the different deiodinases in liver, kidney and brain in the developing rat. In 20-day-old fetuses (E20), glucocorticoids had no effects on circulating thyroid hormone levels despite their clear effects on hepatic and renal deiodinases, thereby indicating that under these conditions circulating thyroid hormone levels are more dependent on thyroidal secretion than on peripheral deiodination. In contrast, in 5-day-old rat pups, DEX did not seem to have any effects on hepatic and renal $T_{3}$ production (via the type I
\end{abstract}

deiodinase), whereas type III deiodinase (D3) activity in both these tissues increased significantly. These observations therefore suggested that the DEX-induced increase in circulating $\mathrm{T}_{3}$ levels is a direct consequence of the increase in plasma $\mathrm{T}_{4}$ levels. In 12-day-old pups (P12), however, the main effect of glucocorticoids on circulating $\mathrm{T}_{3}$ levels was by increasing inner ring deiodination through induction of D3 in both liver and kidney. Finally, in the brain, glucocorticoids stimulated thyroid hormone activity only during a short period of time (between E20 and P12) that largely overlaps with the transient window in time during which brain development is thyroid hormone sensitive. This was in contrast to the E20 and P12 brain, where the glucocorticoid-induced changes in type II deiodinase and D3 seemed to favor a status quo in local $\mathrm{T}_{3}$ availability.

Journal of Endocrinology (2005) 185, 327-336

\section{Introduction}

The thyroid secretes predominantly $3,5,3^{\prime}, 5^{\prime}$-tetraiodothyronine (thyroxine, $\mathrm{T}_{4}$ ) that has to be converted into $3,5,3^{\prime}$-tri-iodothyronine $\left(T_{3}\right)$ in order to bind to a nuclear receptor and exert its full biological activity. This conversion occurs in a wide array of tissues and is catalyzed by a group of selenocysteine-containing oxidoreductases called iodothyronine deiodinases. So far, three types of deiodinases have been identified. The type I deiodinase (D1), which is capable of both activation (outer ring deiodination, $O R D$ ) and inactivation (inner ring deiodination, IRD $)$, is a high $K_{\mathrm{m}}\left(\approx 0.2 \times 10^{-6} \mathrm{M}\right.$ for reverse $\mathrm{T}_{3}\left(\mathrm{rT}_{3}\right)$ ), high $\mathrm{V}_{\max }$ enzyme which is highly sensitive to inhibition by $6-n$-propylthiouracyl (PTU). The type II deiodinase (D2), on the other hand, is a low $K_{\mathrm{m}}$ $\left(\approx 2 \times 10^{-9} \mathrm{M}\right.$ for $\left.\mathrm{T}_{4}\right)$, low $\mathrm{V}_{\max }$ enzyme that only has ORD activity and is not inhibited by PTU. Like D2, the type III deiodinase (D3) is also a selective low $K_{\mathrm{m}}$ $\left(\approx 7 \times 10^{-9} \mathrm{M}\right.$ for $\left.\mathrm{T}_{3}\right)$, low $\mathrm{V}_{\max }$ enzyme that is only capable of IRD and is relatively insensitive to PTU (Bianco et al. 2002).
Glucocorticoids have been demonstrated to affect thyroid function by interacting at both the central and peripheral levels (Pamenter \& Hedge 1980, Rubello et al. 1992, Darras et al. 1999). In addition, in birds it has been established that glucocorticoids regulate thyroid function in an age-dependent manner, acting as inhibitors during post-hatch life and as stimulators during embryonic life (Darras et al. 1996). This occurs mainly by affecting the different peripheral deiodinases, which introduces another level of differential regulation, since these effects are not only age dependent, but also tissue dependent (Darras et al. 1996, Van der Geyten et al. 1999, 2001). In mammals, however, the situation is less clear. In adult humans, glucocorticoid administration results in a decrease in plasma $T_{3}$ levels together with an increase in $\mathrm{rT}_{3}$ levels, whereas circulating $T_{4}$ generally remains unaffected, indicating that the overall effect is a shift from ORD to IRD (Duick et al. 1974, Chopra et al. 1975, Westgren et al. 1977, Lopresti et al. 1989), presumably through stimulation of D3. Although in adult rats plasma $\mathrm{T}_{3}$ remains unaffected, $\mathrm{T}_{3}$ metabolic clearance rate is reduced significantly in glucocorticoid- versus saline-treated animals 
(Kaplan \& Utiger 1978, Cavalieri et al. 1984, Jennings \& Ferguson 1984). In contrast to humans, these changes are linked to a glucocorticoid-induced decrease in hepatic D1 activity (Balsam \& Ingbar 1978). However, in vitro, a number of studies have demonstrated that glucocorticoids have the opposite effect and induce both D1 activity and D1 mRNA expression in rat hepatocytes (Menjo et al. 1993, Davies et al. 1996). So far it remains unclear as to what is the cause behind this discrepancy. Also in NRK52E kidney cells, dexamethasone (DEX) increases D1 activity and mRNA expression (Davies et al. 1996), whereas in pituitary tumor cells DEX alone has no effect on D1 mRNA levels (Maia et al. 1995). Whether these observations, as in avian species, point to a tissue- or even an age-dependent effect of glucocorticoids on peripheral thyroid hormone metabolism remains to be investigated. For D2, such a differential regulation seems to exist. Recent in vitro data have demonstrated that both in rat and mouse pituitary cells D2 mRNA and activity are upregulated after glucocorticoid treatment (Kim et al. 1998, Araki et al. 2003), whereas in mouse HC11 mammary gland cells the opposite effects have been observed (Song \& Oka 2003). Although glucocorticoids have been reported to downregulate D3 expression in rat brown fat vascularstromal cells (Hernandez \& St Germain 2002), to our knowledge these are the only data available concerning this topic in mammals.

The sometimes conflicting data between the different mammalian models used, including the discrepancies between the in vivo and in vitro systems, as well as the limited number of embryonic studies, make it hard to come to clear-cut conclusions concerning the role of glucocorticoids in the regulation of iodothyronine deiodination in mammals, especially during embryonic development. Due to the large variety in modes of administration and dosages used, comparison with data obtained in other well-studied species in this respect (e.g. the chicken) are also difficult and not always without bias. We therefore decided to investigate the acute effects of a single intravenous dose of DEX on circulating thyroid hormone levels and peripheral deiodinase activities in the developing rat. Although the rat is not always considered the best mammalian model in this respect (Darras et al. 1999, Wassen et al. 2004), it was our model of choice since most of the data concerning the regulation of iodothyronine deiodinases by glucocorticoids were obtained using the rat or rat-derived cell lines. We purposely limited the time-frame of our study to $2-4 \mathrm{~h}$ post-injection because we were primarily interested in the direct effects of glucocorticoids on thyroid hormone metabolism, and therefore wanted to avoid the possibility that changes in thyroid hormone levels would interfere with the glucocorticoid-induced changes in deiodinase activity. In addition, we decided to focus on day 20 of embryonic development (E20) and postnatal day 12 (P12), because from a developmental point of view these stages roughly delineate the time-frame during which develop- ment (especially neural development) is extremely sensitive to thyroid hormones (Bernal 2002, Anderson et al. 2003). We also included postnatal day 5 (P5) because this stage corresponds to the human fetus or the chicken embryo just prior to birth or hatching respectively.

\section{Materials and Methods}

\section{Animals}

The Wistar (HsdCbp:WU) rats (Harlan, Horst, The Netherlands) used in these experiments were kept in a temperature $\left(22^{\circ} \mathrm{C}\right)$ - and light $(14 \mathrm{~h}$ of light/day)controlled room with free access to tap water and a standard diet. Fetal and neonatal rats were obtained by in-house breeding. For determination of the fetal age, the presence of a cervical plug in the morning was taken to be day 1 of pregnancy. Neonatal pups were kept with their mothers in separate cages, under identical conditions as before (see above). The University Ethical Committee for Animal Experiments approved all experimental animal manipulations.

\section{Experimental design}

For the experiments on E20 fetal rats, pregnant dams were weighed and anesthetized using $0 \cdot 1 \mathrm{ml} / 100 \mathrm{~g}$ body weight Nembutal (sodium pentobarbital, $60 \mathrm{mg} / \mathrm{ml}$ ). An incision was made in the abdominal cavity and part of the uterus, after which both the amniotic and chorionic membranes enveloping the fetuses were removed. DEX (SigmaAldrich, Bornem, Belgium) was dissolved in a small volume of ethanol ( $2 \%$ of final volume) and further diluted using $0.9 \% \mathrm{NaCl}$. Individual fetuses were injected via the vena umbilicalis with either $50 \mu \mathrm{l}$ vehicle alone (control) or $5 \mu \mathrm{g}$ DEX $( \pm 1.5 \mu \mathrm{g} / \mathrm{g}$ body weight), a dose that corresponds to that used in previously reported rat (Cavalieri et al. 1984, Jennings \& Ferguson 1984) and chicken studies (Darras et al. 1996, Van der Geyten et al. 1999, 2001). Two hours after this injection, blood was collected into heparinized tubes via the fetal vena subclavia and liver, brain and kidney were collected, immediately frozen in liquid nitrogen and stored at $-80{ }^{\circ} \mathrm{C}$. Plasma was stored at $-20{ }^{\circ} \mathrm{C}$. To avoid dehydration and hypothermia of the fetuses during the experiment, they were sprinkled at regular time-intervals with prewarmed $0.9 \% \mathrm{NaCl}$ whereas body temperature of the pregnant dams and the fetuses was kept stable using an electrical heating pad. As an additional control (non-injected, NI), blood and tissue samples were also collected from E20 rat fetuses immediately following decapitation of the pregnant dams. Hence, these fetuses were not submitted to any experimental manipulation.

For the experiments using $\mathrm{P} 5$ and $\mathrm{P} 12$ rat pups, $50 \mu \mathrm{l}$ vehicle (control) or $50 \mu \mathrm{g}$ DEX (1.5-3 $\mu \mathrm{g} / \mathrm{g}$ body weight 
for P12 and P5 pups respectively) were injected intraperitoneally. To take into account the different mode of administration (intravenous versus intraperitoneal injection) between fetuses and pups, blood as well as tissues from P5 and P12 rat pups (killed by decapitation) were collected not at $2 \mathrm{~h}$ but at $4 \mathrm{~h}$ after the injection.

Due to the variable number of fetuses per mother, the number of samples analyzed per treatment group also varied. For E20 rats, this resulted in $n=16$ (two mothers) for the NI fetuses, $n=29$ (four mothers) for the salinetreated animals and $n=38$ (four mothers) for the DEXtreated rat fetuses. For the experiments with P5 pups (seven mothers), $n=34$ for both the saline- and DEXtreated groups. For the P12 experiment (six mothers), $n=28$ for the saline- treated pups and $n=29$ for the DEX-treated pups. In the latter experiments, half the pups from each mother were treated with DEX and the other half served as controls. In order to verify the data obtained, the entire study was repeated on an independent batch of animals, with $n=15$ for the NI fetuses, $n=20$ for the saline-treated animals and $n=20$ for the DEX-treated rat fetuses. For the experiments with P5 pups, $n=25$ for the saline-treated pups and $n=26$ for the DEX-treated pups. For the P12 experiment, $n=15$ for both the saline- and DEX-treated groups. This study confirmed the results from the first study, except for the D2 and D3 activities in P12 brain samples. Therefore, from the data obtained in the second study only the latter are discussed separately.

\section{Thyroid hormone and deiodinase assays}

$\mathrm{T}_{4}$ and $\mathrm{T}_{3}$ concentrations in plasma were determined by specific RIAs as defined previously (Van der Geyten et al. 2001).

Preparation of homogenates or microsomal fractions and measurement of D1, D2 and D3 activities were performed as described previously (Darras et al. 1992, 1996). In short, D1 activity was determined by measuring the radioiodide released from $\left[3^{\prime}, 5^{\prime}-{ }^{125} \mathrm{I}\right] \mathrm{rT}_{3}$. Incubation mixtures contained 50000 c.p.m. $\left[3^{\prime}, 5^{\prime}-{ }^{125} \mathrm{I}_{\mathrm{rT}}, 1 \mu \mathrm{M} \mathrm{rT}_{3}, 100 \mu \mathrm{g}\right.$ protein $/ \mathrm{ml}$ and $10 \mathrm{mM}$ dithiothreitol (DTT) in sodium phosphate buffer ( $\mathrm{pH} 7 \cdot 2)$ and $2 \mathrm{mM}$ EDTA. Reactions were stopped, and iodothyronines were precipitated by successive addition of $100 \mu \mathrm{l} 5 \%$ bovine serum albumin and $500 \mu \mathrm{l} 10 \%$ trichloroacetic acid at $0{ }^{\circ} \mathrm{C}$. After centrifugation $(3500 \mathrm{~g}, 10 \mathrm{~min}), 500 \mu \mathrm{l}$ of the supernatant was counted in a $\gamma$-counter (Gammamaster, LKB Wallac, Erlangen, Germany). D2 activity was determined by measuring the radioiodide released from $\left[3^{\prime}, 5^{\prime}-{ }^{125} \mathrm{I}\right] \mathrm{T}_{4}$. Incubation mixtures contained 50000 c.p.m. $\left[3^{\prime}, 5^{\prime}{ }^{\prime}{ }^{125} \mathrm{I}\right] \mathrm{T}_{4}$, $1 \mathrm{nM} \mathrm{T}_{4}, 1 \mathrm{mg}$ protein/ml, $100 \mathrm{nM} \mathrm{T}_{3}, 0 \cdot 1 \mathrm{mM} \mathrm{PTU}$ and $50 \mathrm{mM}$ DTT in sodium phosphate buffer $(\mathrm{pH} \mathrm{7.2)}$ and $2 \mathrm{mM}$ EDTA. The rest of the assay was identical to the D1 enzyme assay. To exclude possible interference from residual D1 activity, the ORD of $\mathrm{T}_{4}$ was also measured in the presence of $100 \mathrm{nM} \mathrm{T}_{4}$. At this substrate concentration, the D2 enzyme was saturated, so that all ${ }^{-}$measured in the assay was derived from the ORD of $\left[3^{\prime}, 5^{\prime}-{ }^{125} \mathrm{I}\right] \mathrm{T}_{4}$ by D1. Only when $\mathrm{I}^{-}$production was absent or minimal in the presence of $100 \mathrm{nM} \mathrm{T} \mathrm{T}_{4}$ was the enzyme activity in the assay using $1 \mathrm{nM} \mathrm{T}_{4}$ considered to be true D2 activity. For D3 activity, incubation mixtures contained 150000 c.p.m. $\left[3^{\prime}{ }^{125}{ }^{15} \mathrm{~T}_{3}, 10 \mathrm{nM} \mathrm{T} \mathrm{T}_{3}\right.$ (brain) or $1 \mathrm{nM} \mathrm{T}$ (liver and kidney), $1 \mu \mathrm{M} \mathrm{rT}_{3}, 125 \mu \mathrm{g}$ protein $/ \mathrm{ml}$ (liver), $250 \mu \mathrm{g}$ protein $/ \mathrm{ml}$ (brain) or $1 \mathrm{mg}$ protein $/ \mathrm{ml}$ (kidney), $0.1 \mathrm{mM}$ PTU and $50 \mathrm{mM}$ DTT in sodium phosphate buffer ( $\mathrm{pH} 7 \cdot 2$ ) and $2 \mathrm{mM}$ EDTA. Incubation was stopped by the addition of $300 \mu \mathrm{l}$ ice-cold methanol. After centrifugation $(3500 \mathrm{~g}, 10 \mathrm{~min}), 200 \mu \mathrm{l}$ supernatant aliquots were transferred to vials containing $250 \mu \mathrm{l}$ ammonium acetate buffer $(0.02 \mathrm{M}, \mathrm{pH} 4 \cdot 0)$. Labeled iodothyronines and $\mathrm{I}^{-}$ were separated by HPLC (Eelkman-Rooda et al. 1989). For this, $80 \mu \mathrm{l}$ of the mixture was injected onto a C18 column (Nucleosil 100-5 C18, Filterservice, Eupen, Belgium) and eluted with a $28 \% / 72 \%(\mathrm{v} / \mathrm{v})$ mixture of acetonitrile and ammonium acetate buffer at a flow rate of $1 \mathrm{ml} / \mathrm{min}$. Radioactivity was assessed with an on-line radioactivity monitor (LB 506 C-1; Perkin Elmer, Oosterhout, The Netherlands), and peaks were integrated using the RadioStar 3.0 software (Berthold Technologies, Bad Wildbad, Germany).

Plasma $\mathrm{T}_{3}$ and $\mathrm{T}_{4}$ levels are expressed as $\mathrm{pmol} / \mathrm{ml}$, whereas all activities were calculated as the amount of substrate deiodinated/mg protein per min.

\section{Results}

For the study on E20 rat fetuses, plasma $\mathrm{T}_{3}$ (control: $0.748 \pm 0.043 \mathrm{pmol} / \mathrm{ml}$, DEX: $0.642 \pm 0.041 \mathrm{pmol} / \mathrm{ml}$, $P=0.121$ ) and $\mathrm{T}_{4}$ (control: $39.87 \pm 5.97 \mathrm{pmol} / \mathrm{ml}$, DEX: $31.95 \pm 5 \cdot 16 \mathrm{pmol} / \mathrm{ml}, \quad P=0.219)$ levels did not differ between the pregnant dams whose fetuses received saline or those whose fetuses were treated with DEX. In addition, the procedure (anesthetic+surgery) itself resulted in a decrease $\left(P<0 \cdot 001\right.$, ANOVA) in plasma $\mathrm{T}_{4}$ levels (NI: $6.68 \pm 0.44 \mathrm{pmol} / \mathrm{ml}$, control: $3.61 \pm 0.44 \mathrm{pmol} / \mathrm{ml}$, kidney D1 activity (NI: 9.63 $\pm 0.26 \mathrm{pmol} \mathrm{rT}_{3} / \mathrm{mg}$ per min, control: $7 \cdot 01 \pm 0 \cdot 52 \mathrm{pmol} \mathrm{rT}_{3} / \mathrm{mg}$ per min) and brain D2 activity (NI: $0.360 \pm 0.015 \mathrm{fmol} \mathrm{T}_{4} / \mathrm{mg}$ per min, control: $0.228 \pm 0.009 \mathrm{fmol} \mathrm{T}_{4} / \mathrm{mg}$ per min), whereas all other parameters measured remained unaffected.

In E20 rat fetuses, DEX administration had no effect on plasma $T_{3}$ and $T_{4}$ levels when compared with the vehicle (saline)-injected controls (Fig. 1A and B). In P5 rat pups, however, both $\mathrm{T}_{3}$ and $\mathrm{T}_{4}$ were increased $4 \mathrm{~h}$ after glucocorticoid treatment (Fig. 1C and D). This was again in contrast to P12 pups, in which plasma $\mathrm{T}_{3}$ decreased significantly after DEX treatment, although circulating $\mathrm{T}_{4}$ levels remained unaffected in comparison with the saline-treated controls (Fig. 1E and F). 

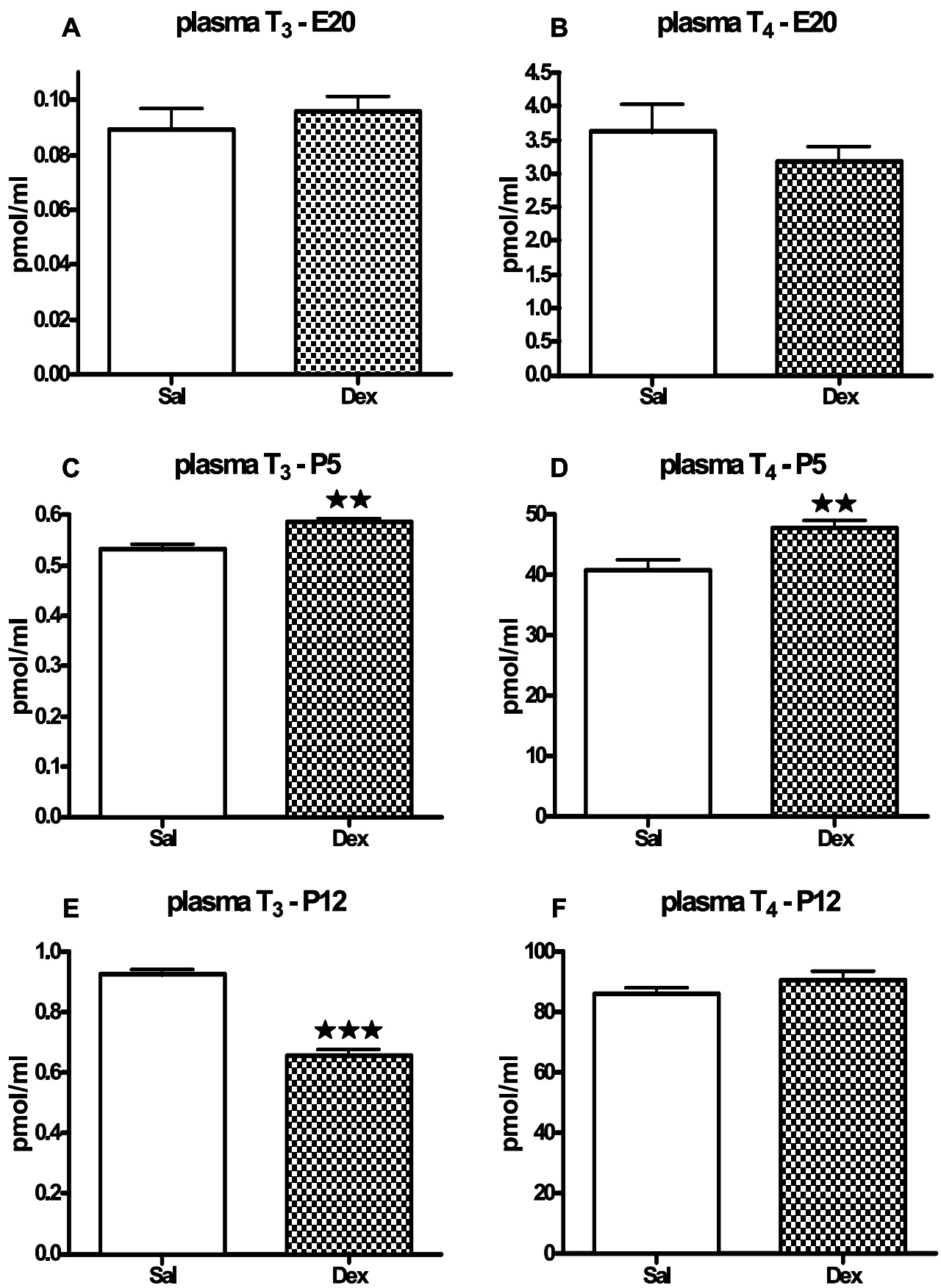

Figure 1 Effects of intravenous administration of $5 \mu \mathrm{g}(\mathrm{E} 20,2 \mathrm{~h})$ or $50 \mu \mathrm{g}$ (P5 and P12, 4 h) DEX (Dex) on plasma $(A, C$ and $E) T_{3}$ and $(B, D$ and $F) T_{4}$, in $(A$ and $B) E 20$ rat fetuses and $(C$ and $D) P 5$ or $(E$ and $F$ ) P12 rat pups. (Saline treated $=$ Sal). Data are expressed as the means \pm S.E.M. $\left(n_{\mathrm{E} 20, \text { Sal }}=29, n_{\mathrm{E} 20 \text {,Dex }}=38\right.$, $\left.n_{\mathrm{P} 5, \text { Sal }}=34, n_{\mathrm{P} 5, \mathrm{Dex}}=34, n_{\mathrm{P} 12 \text {, Sal }}=28, n_{\mathrm{P} 12 \text {,Dex }}=29\right) .{ }^{* *} P<0 \cdot 01$ and ${ }^{* * *} P<0 \cdot 001$. (unpaired two-tailed $t$-test).

In vitro hepatic D1 activity was decreased in DEXtreated rat fetuses (Fig. 2A), whereas postnatal glucocorticoid administration had no effect on hepatic D1 (Fig. 2C and E). Similarly to D1, in vitro D3 activity was decreased in the liver of DEX-treated rat fetuses (Fig. 2B), whereas in both the P5 and P12 pups glucocorticoids increased hepatic D3 (Fig. 2D and F).

In accordance with the results in the liver, glucocorticoid administration resulted in a decreased D1 activity in the kidney of E20 fetuses (Fig. 3A), whereas in P5 and 

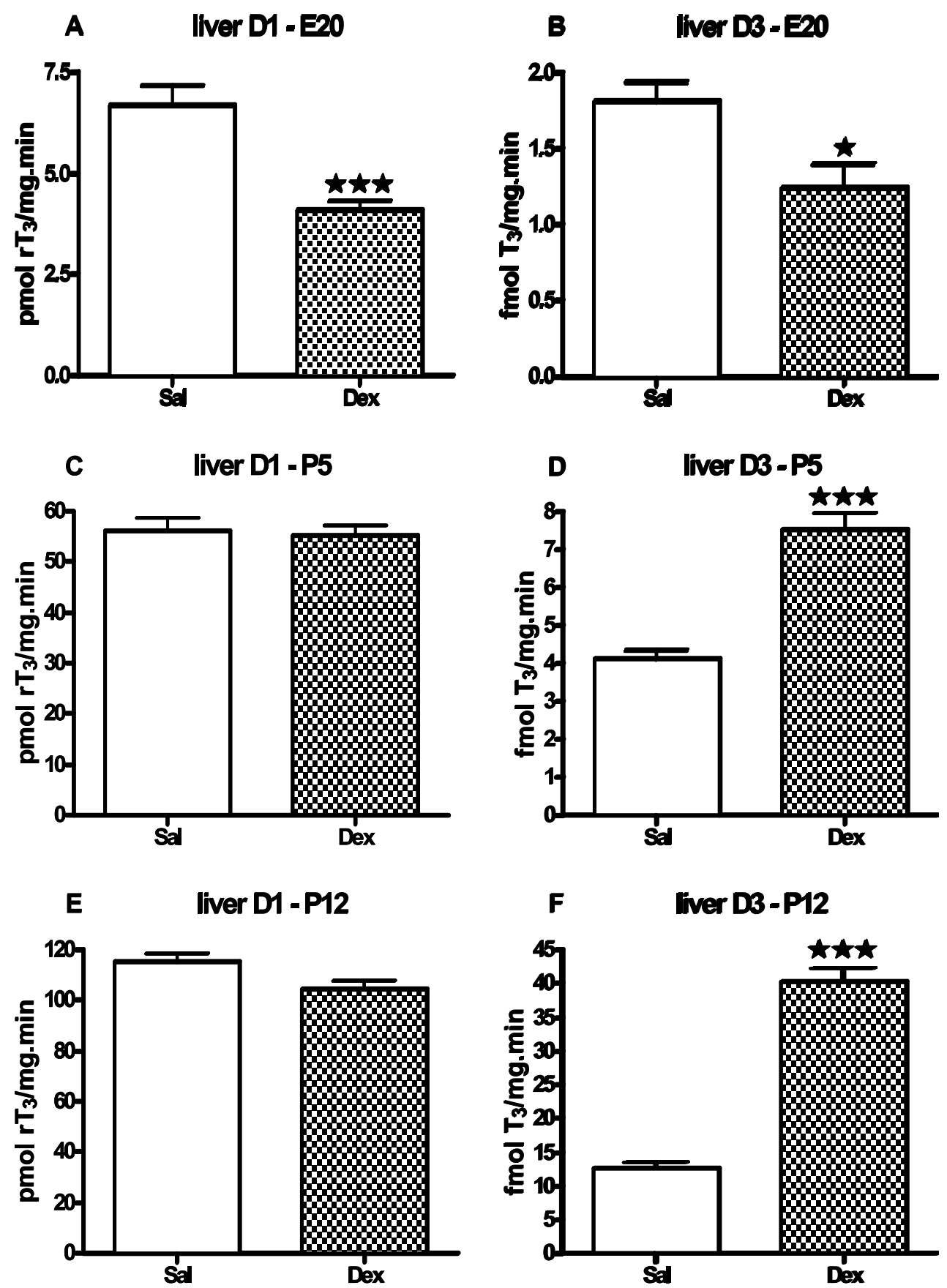

Figure 2 Effects of intravenous administration of $5 \mu \mathrm{g}(\mathrm{E} 20,2 \mathrm{~h})$ or $50 \mu \mathrm{g}$ (P5 and P12, 4 h) DEX (Dex) on in vitro hepatic (A, C and E) D1 and (B, D and F) D3 activity, in (A and B) E20 rat fetuses and (C and D) $\mathrm{P} 5$ or $(\mathrm{E}$ and F) P12 rat pups. (Saline treated $=$ Sal $)$. Data are expressed as the means \pm S.E.M. $\left(n_{\mathrm{E} 20 \text {,Sal }}=29\right.$, $n_{\mathrm{E} 20, \text { Dex }}=38, n_{\mathrm{P} 5, \mathrm{Sal}}=34, n_{\mathrm{P} 5, \text { Dex }}=34, n_{\mathrm{P} 12, \mathrm{Sal}}=28, n_{\mathrm{P} 12, \mathrm{Dex}}=29$ ). ${ }^{*} P<0 \cdot 05$ and ${ }^{* *} P<0 \cdot 001$ (unpaired two-tailed $t$-test).

P12 kidneys DEX had no effect on in vitro D1 activity in comparison with control kidneys (Fig. 3C and E). Likewise, renal D3 was also increased in P5 and P12 treated rat pups (Fig. 3D and F), although in E20 fetuses
D3 activity remained unaffected when compared with the saline-injected controls (Fig. 3B).

In the brain, glucocorticoids induced an increase in in vitro D2 activity at both the E20 and P5 stages 

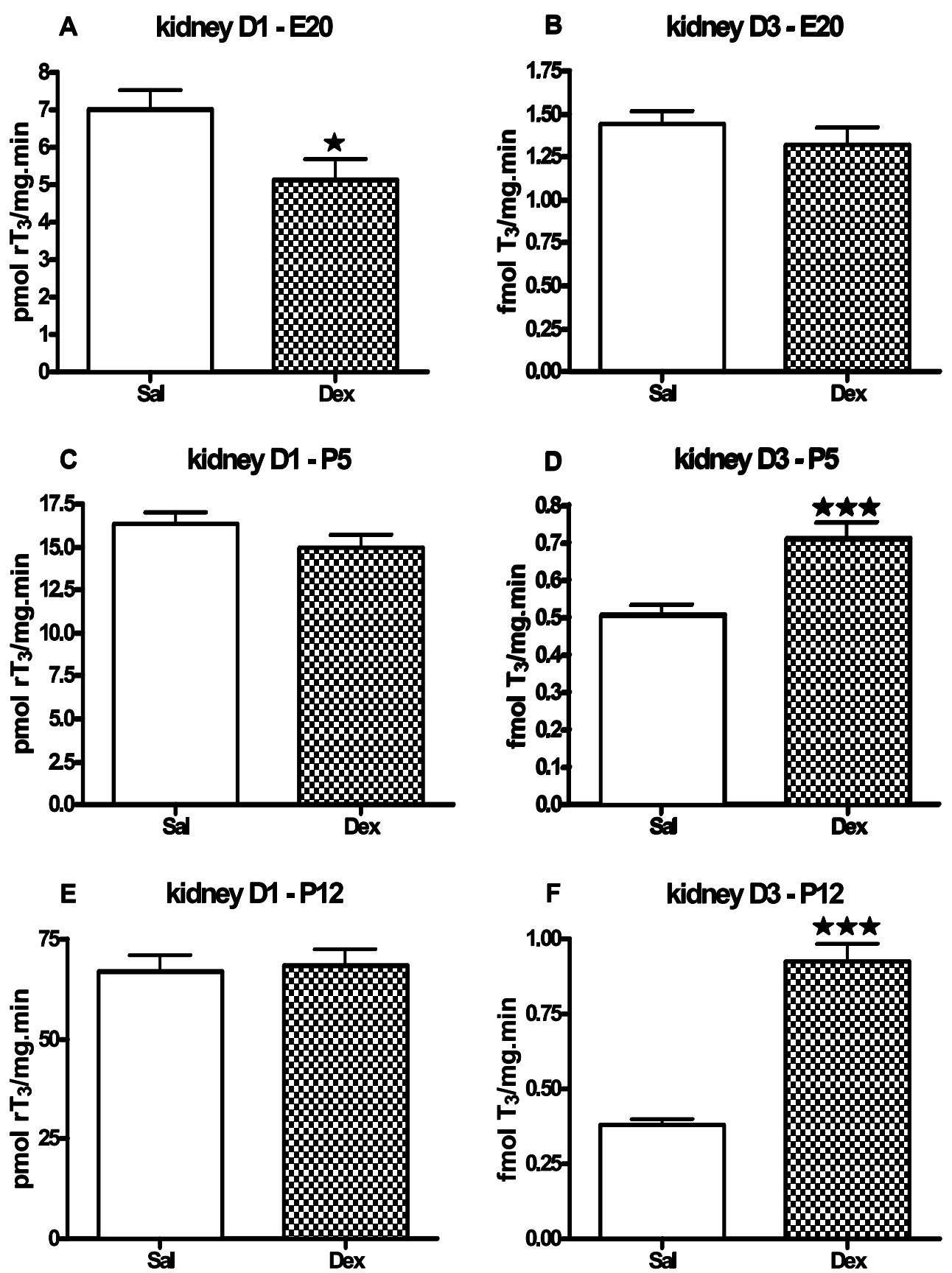

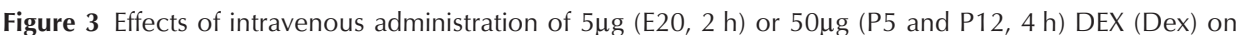
in vitro renal (A, C and E) D1 and (B, D and F) D3 activity, in ( $A$ and B) E20 rat fetuses and (C and D) P5 or $\left(E\right.$ and F) P12 rat pups. (Saline treated $=$ Sal). Data are expressed as the means \pm S.E.M. $\left(n_{\mathrm{E} 20 \text {,Sal }}=29\right.$, $\left.n_{\mathrm{E} 20, \text { Dex }}=38, n_{\mathrm{P} 5, \text { Sal }}=34, n_{\mathrm{P} 5, \text { Dex }}=34, n_{\mathrm{P} 12, \mathrm{Sal}}=28, n_{\mathrm{P} 12, \mathrm{Dex}}=29\right) .{ }^{*} P<0 \cdot 05$ and ${ }^{* * *} P<0 \cdot 001$ (unpaired two-tailed $t$-test).

(Fig. 4A and C). At P12, D2 decreased following DEX administration (Fig. 4E), although this could not be confirmed in the duplicate study where D2 remained unaltered by glucocorticoids at this developmental stage (control: $0.532 \pm 0.045 \mathrm{fmol} \mathrm{T}_{4} / \mathrm{mg}$ per min, DEX: $0.514 \pm 0.027 \mathrm{fmol}_{4} / \mathrm{mg}$ per min). For D3, the situation was somewhat more complex. In E20 fetuses, DEX increased in vitro D3 activity (Fig. 4B), whereas 

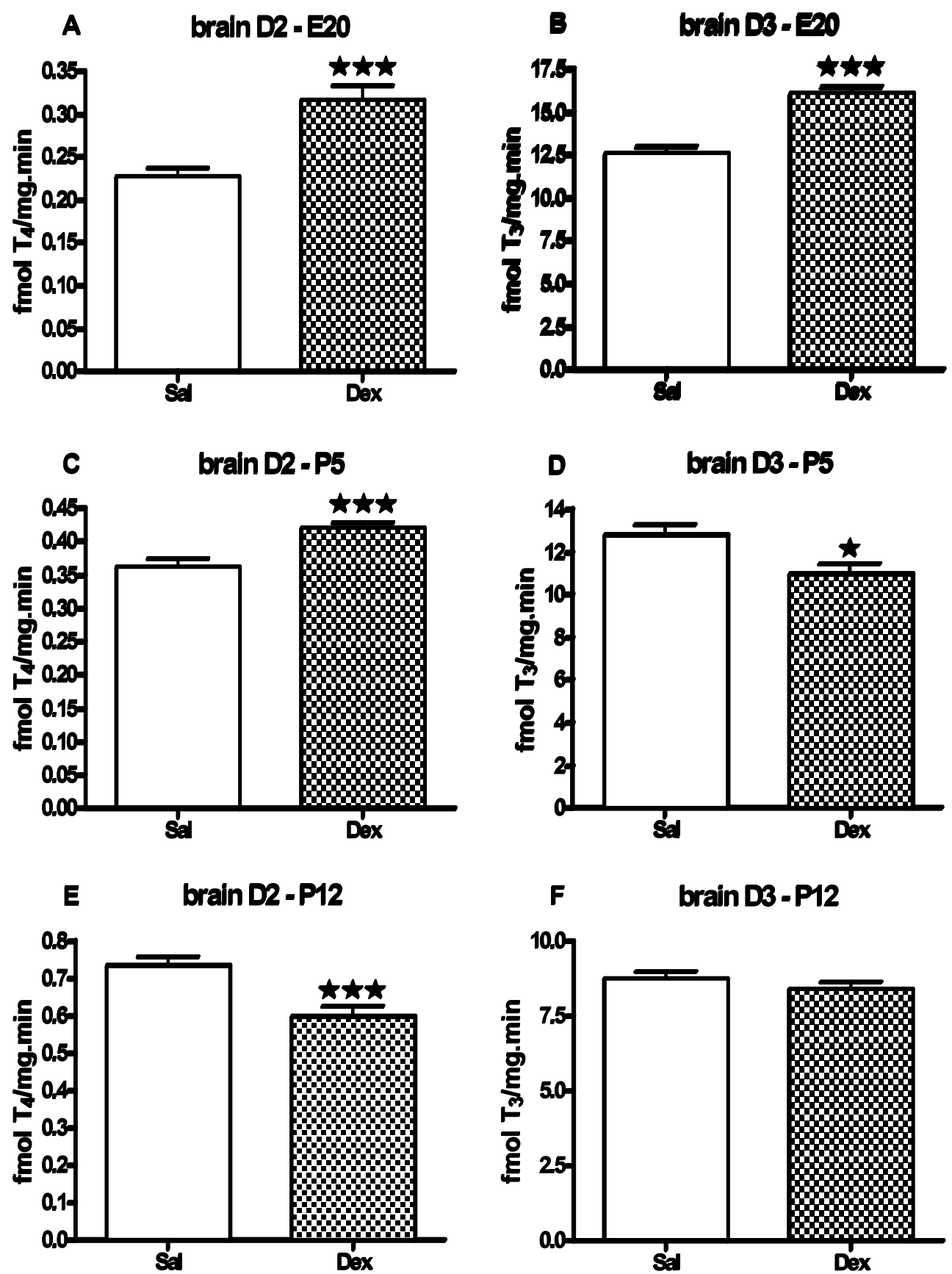

Figure 4 Effects of intravenous administration of $5 \mu \mathrm{g}(\mathrm{E} 20,2 \mathrm{~h})$ or $50 \mu \mathrm{g}$ (P5 and P12, 4 h) DEX (Dex) on in vitro brain (A, C and E) D2 and (B, D and F) D3 activity, in (A and B) E20 rat fetuses and (C and D) P5 or (E and F) P12 rat pups. (Saline treated $=$ Sal). Data are expressed as the means \pm S.E.M. $\left(n_{\mathrm{E} 20, \text { Sal }}=29\right.$, $n_{\mathrm{E} 20, \text { Dex }}=38, n_{\mathrm{P} 5 \text {, Sal }}=34, n_{\mathrm{P} 5, \text { Dex }}=34, n_{\mathrm{P} 12, \mathrm{Sal}}=28, n_{\mathrm{P} 12, \text { Dex }}=29$ ). ${ }^{*} P<0 \cdot 05$ and ${ }^{* * *} P<0 \cdot 001$ (unpaired two-tailed $t$-test).

it decreased D3 in P5 pups (Fig. 4D). Finally, in P12 pups DEX had no effect on brain D3 (Fig. 4F). The latter result, however, was again different in the duplicate study, where D3 activity showed a moderate, albeit significant increase, after DEX administration to P12 rat pups (control: $10 \cdot 39 \pm 0 \cdot 36 \mathrm{fmol} \mathrm{T}_{3} / \mathrm{mg}$ per min, DEX: $11.85 \pm 0.46 \mathrm{fmol} \mathrm{T}_{3} / \mathrm{mg}$ per min, $P<0 \cdot 05)$. 


\section{Discussion}

The most striking result of the present study was that glucocorticoids affected circulating thyroid hormone levels as well as peripheral deiodination differently at all developmental stages studied. That in E20 rat pups circulating $\mathrm{T}_{3}$ and $\mathrm{T}_{4}$ levels were not affected by DEX despite the significant changes in hepatic and renal deiodination, could be the result of maternal hormone levels masking potential changes in fetal plasma thyroid hormone concentrations. However, at E20 the rat fetal thyroid is already fully active and maternal $\mathrm{T}_{4}$ only accounts for $17.5 \%$ of the fetal extrathyroidal $\mathrm{T}_{4}$ pool (Morreale de Escobar et al. 1990, 2004), thereby indicating that only minor changes in fetal plasma $T_{3}$ and $T_{4}$ would be masked by the unchanged maternal levels. Taken together, these data therefore suggested that in the days just prior to parturition the control of circulating thyroid hormone levels seems more dependent on fetal thyroidal secretion than on peripheral deiodination, as is generally assumed to be the case. In contrast to the fetal situation, DEX injection increased both plasma $T_{3}$ and $T_{4}$ in $\mathrm{P} 5$ rat pups and this without affecting hepatic and renal D1. Although peripheral $T_{3}$ production did not seem to be affected by glucocorticoids at this stage, the increase in thyroidal $\mathrm{T}_{4}$ secretion alone together with an unaltered D1 activity was probably sufficient to account for the increase in circulating $\mathrm{T}_{3}$ levels. In $\mathrm{P} 12$ pups, however, DEX no longer affected circulating $\mathrm{T}_{4}$ levels, whereas it significantly decreased plasma $\mathrm{T}_{3}$ concentrations. Although previous experiments, using both adult and $\mathrm{P} 7$ rats, indicated that glucocorticoids reduced hepatic $\mathrm{T}_{3}$ production (Jennings \& Ferguson 1984, McCann et al. 1984), our results suggested that in P12 rat pups the DEX-induced decrease in plasma $T_{3}$ levels is more likely due to the increased hepatic and possibly also renal $\mathrm{T}_{3}$ degradation (via D3) without changes in peripheral $T_{3}$ production. A similar mechanism has been proposed to explain the glucocorticoid-induced decrease in plasma $\mathrm{T}_{3}$ levels in man, although so far no direct experimental proof has been provided for this hypothesis (Chopra et al. 1975, Westgren et al. 1977, Lopresti et al. 1989).

Also in the brain, thyroid hormone metabolism was differentially affected by glucocorticoids depending on the developmental stage at which exposure occurred. At E20, the rise in brain D2 suggested a possible glucocorticoidinduced increase in intracellular $T_{3}$ availability in this tissue. That brain D3 activity also increased simultaneously might indicate that for the brain this increase comes at the wrong time in development and therefore the brain, through induction of the IRD pathway, takes protective measures to counteract this premature increase in local $\mathrm{T}_{3}$ levels. This clearly differs from that which occurs in the brain of $\mathrm{P} 5$ rat pups, where the increased plasma $\mathrm{T}_{3}$ and $\mathrm{T}_{4}$ levels, in combination with the opposing effects of DEX on brain D2 and D3, indicated that in this tissue and at this developmental stage glucocorticoids favor thyroid hormone activation by stimulating the ORD of $\mathrm{T}_{4}$ and inhibiting the IRD of $T_{3}$. Similar results have been found in embryonic birds (Darras et al. 1996, Van der Geyten et al. 2001) and larval amphibians (Darras et al. 2002). Since it has been well established that the brain of early neonatal rats is developmentally equivalent to the 2 nd trimester human fetal brain and to the brain of late embryonic chickens (Sedlácek 1972, Markus et al. 1987, Rostas et al. 1991, Bernal 2002), these results suggested that this glucocorticoid-induced thyroid hormone activation in the brain might represent a development-related and important maturating mechanism that is present across vertebrates. However, at P12, glucocorticoids no longer stimulated brain D2 activity, thereby indicating that glucocorticoids no longer push brain thyroid hormone metabolism towards increasing local $\mathrm{T}_{3}$ levels. This situation probably also persists further in life, since also in P21 pups (McCann et al. 1984) as well as in adult rats (Anguiano et al. 1995) glucocorticoids no longer increase brain D2 activity.

This transient window in time (between E20 and P12) during which rat brain thyroid hormone activity appears to be stimulated by glucocorticoids coincides with some important neurodevelopmental processes, such as neuronal migration, oligodendrocyte development and cerebellar maturation. For example, dendritic arborization of cerebellar Purkinje cells is only sensitive to thyroid hormones during the first 2 weeks postnatal (Anderson et al. 2003), which corresponds to the time-frame during which glucocorticoids stimulate brain thyroid hormone activity. In addition, in the visual cortex, the hypothyroid-induced changes in distribution and number of dendritic spines in pyramidal cells can only be reversed when thyroid hormone replacement is initiated before day 12 , whereas a delay beyond postnatal day 12 results in abnormal adult pyramidal cells (Anderson et al. 2003). These observations indicated that not only thus does there exist a narrow window in time during which brain development is thyroid hormone sensitive (Bernal 2002, Anderson et al. 2003), but this window in time largely overlaps with the period during which glucocorticoids stimulate brain $T_{3}$ availability through opposing effects on brain D2 and D3 activity.

In addition, the current results also demonstrated that D3 is not only regulated in an age-dependent manner by glucocorticoids, but also in a tissue-specific manner. This, however, is less clear for D1 and D2. We did not find a difference between the effects of DEX on hepatic and renal D1 activity at any of the developmental stages studied. However, Maia et al. (1995) demonstrated, in pituitary tumor cells, that DEX alone had no effect on D1 mRNA expression, whereas it enhanced $\mathrm{T}_{3}$-stimulated D1 mRNA levels. Although this may point to some degree of tissue specificity, it might also be an observation that is only relevant for in vitro systems. Indeed, in cultured 
liver and kidney cells also, glucocorticoids alone or in combination with $\mathrm{T}_{3}$ increase D1 mRNA and/or activity (Davies et al. 1996, Menjo et al. 1993, Yamaguchi et al. 1999). So far, the mechanisms underlying the discrepancies between the in vivo and in vitro effects of glucocorticoids have not been elucidated, so at the moment the question concerning the tissue-specific effects of DEX on D1 remains unanswered. Similarly, the question as to whether glucocorticoids have tissue-specific effects on D2 or not cannot be answered based on the presented data alone. Recent reports have indicated that in rat (GH3 and GC cells) and mice (AtT-20 cells) pituitary cells D2 mRNA levels are also increased after glucocorticoid treatment (Kim et al. 1998, Araki et al. 2003), whereas in mouse HC11 (mammary gland) cells DEX decreases D2 activity, D2 mRNA levels and D2 promoter activity (Song \& Oka 2003). Although these data could be indicative for tissue-specific regulation, additional in vivo experiments will be required if conclusive evidence is to be obtained.

In conclusion, the presented data have demonstrated that, in the developing rat, glucocorticoids regulate peripheral thyroid hormone metabolism in both a tissue- and age-dependent manner. In E20 rat fetuses, glucocorticoids had no effects on circulating thyroid hormone levels despite their clear effects on hepatic and renal deiodinases, thereby indicating that under these conditions circulating thyroid hormone levels are more dependent on thyroidal secretion than on peripheral deiodination. In contrast, in P5 rat pups, DEX did not seem to have any effects on hepatic and renal $\mathrm{T}_{3}$ production (via D1), whereas D3 activity in both these tissues increased significantly. These observations therefore suggested that the DEX-induced increase in circulating $\mathrm{T}_{3}$ levels is a direct consequence of the increase in plasma $\mathrm{T}_{4}$ levels. In P12 pups, however, the main effect of glucocorticoids on circulating $\mathrm{T}_{3}$ levels is by increasing the IRD pathway through induction of D3 in both liver and kidney. Finally, in the brain, glucocorticoids stimulate thyroid hormone activity only during a short period of time (between E20 and P12) that largely overlaps with the transient window in time during which brain development is thyroid hormone sensitive.

\section{Acknowledgements}

We wish to thank $F$ Voets for performing the animal manipulations, and W Van Ham and L Noterdaeme for their technical assistance during the experiments. This study was supported by grants G.0170.02 and G.0272.04 from the Fund for Scientific Research, Flanders. S Vd G was supported by the Fund for Scientific Research, Flanders. The authors declare that there is no conflict of interest that would prejudice the impartiality of this scientific work.

\section{References}

Anderson GW, Schoonover CM \& Jones SA 2003 Control of thyroid hormone action in the developing rat brain. Thyroid 13 1039-1056. Anguiano B, Quintanar A, Luna M, Navarro L, Ramírez Del Angel A, Pacheco P \& Valverde-R C 1995 Neuroendocrine regulation of adrenal gland and hypothalamus 5 'deiodinase activity. II. Effects of splanchnicotomy and hypophysectomy. Endocrinology 136 3346-3352.

Araki O, Morimura T, Ogiwara T, Mizuma H, Mori M \& Murakami M 2003 Expression of type 2 iodothyronine deiodinase in corticotropin-secreting mouse pituitary tumor cells is stimulated by glucocorticoid and corticotropin-releasing hormone. Endocrinology 144 4459-4465.

Balsam A \& Ingbar SH 1978 The influence of fasting, diabetes, and several pharmacological agents on the pathways of thyroxine metabolism in rat liver. Joural of Clinical Investigation 62 415-424.

Bernal J 2002 Thyroid hormones and brain development. In Hormones, Brain and Behavior. Volume IV: Development of Hormone-Dependent Neuronal Systems, pp 543-573. Eds DW Pfaff DW, AP Arnold, AM Etgen, SE Fahrbach \& RT Rubin. San Diego: Academic Press.

Bianco AC, Salvatore D, Gereben B, Berry MJ \& Larsen PR 2002 Biochemistry, cellular and molecular biology, and physiological roles of iodothyronine selenodeiodinases. Endocrine Reviews 23 38-89.

Cavalieri RR, Castle JN \& McMahon FA 1984 Effects of dexamethasone on kinetics and distribution of triiodothyronine in the rat. Endocrinology 114 215-221.

Chopra IJ, Williams DE, Orgiazzi J \& Solomon D 1975 Opposite effects of dexamethasone on serum concentrations of $3,3^{\prime}, 5^{\prime}$-triiodothyronine (reverse $\mathrm{T}_{3}$ ) and 3,3',5-triiodothyronine $\left(\mathrm{T}_{3}\right)$. Journal of Clinical Endocrinology and Metabolism 41 911-920.

Darras VM, Visser TJ, Berghman LR \& Kühn ER 1992 Ontogeny of type I and type III deiodinase activities in embryonic and posthatch chicks: relationship with changes in plasma triiodothyronine and growth hormone levels. Comparative Biochemistry and Physiology A 103 131-136.

Darras VM, Kotanen SP, Geris KL, Berghman LR \& Kühn ER 1996 Plasma thyroid hormone levels and iodothyronine deiodinase activity following an acute glucocorticoid challenge in embryonic compared with posthatch chickens. General and Comparative Endocrinology 104 203-212.

Darras VM, Hume R \& Visser TJ 1999 Regulation of thyroid hormone metabolism during fetal development. Molecular and Cellular Endocrinology 151 37-47.

Darras VM, Van der Geyten S, Cox C, Segers IB, De Groef B \& Kühn ER 2002 Effects of dexamethasone treatment on iodothyronine deiodinase activities and on metamorphosis-related morphological changes in the axolotl (Ambystoma mexicanum). General and Comparative Endocrinology 127 157-164.

Davies PH, Sheppard MC \& Franklyn JA 1996 regulation of type I 5 -deiodinase by thyroid hormone and dexamethasone in rat liver and kidney cells. Thyroid 6 221-228.

Duick DS, Warren DW, Nicoloff JT, Otis CL \& Croxson MS 1974 Effect of single dose dexamethasone on the concentration of serum triiodothyronine in man. Journal of Clinical Endocrinology and Metabolism 39 1151-1154.

Eelkman-Rooda SJ, Otten MH, van Loon MAC, Kaptein E \& Visser TJ 1989 Metabolism of triiodothyronine in rat hepatocytes. Endocrinology 125 2187-2197.

Hernandez A \& St Germain L 2002 Dexamethasone inhibits growth factor-induced type 3 deiodinase activity and mRNA expression in a cultured cell line derived from rat neonatal brown fat vascular-stromal cells. Endocrinology 143 2652-2658.

Jennings A \& Ferguson DC 1984 Effect of dexamethasone on triiodothyronine production in the perfused rat liver and kidney. Endocrinology 114 31-36.

Kaplan MM \& Utiger RD 1978 Iodothyronine metabolism in rat liver homogenates. Journal of Clinical Investigation 61 459-471. 
Kim S-W, Harney JW \& Larsen PR 1998 Studies on the hormonal regulation of type $25^{\prime}$-iodothyronine deiodinase messenger ribonucleic acid in pituitary tumor cells using semiquantitative reverse transcription-polymerase chain reaction. Endocrinology 139 4895-4905.

Lopresti JS, Eigen A, Kaptein E, Anderson KP, Spencer CA \& Nicoloff JT 1989 Alterations in 3,3',5'-triiodothyronine metabolism in response to propylthiouracil, dexamethasone, and thyroxine administration in man. Joural of Clinical Investigation 84 1650-1656.

McCann UD, Shaw EA \& Kaplan MM 1984 Iodothyronine deiodination reaction types in several rat tissues: effects of age, thyroid status, and glucocorticoid treatment. Endocrinology 114 1513-1521.

Maia AL, Harney JW \& Larsen PR 1995 Pituitary cells respond to thyroid hormone by discrete, gene-specific pathways. Endocrinology $1361488-1494$.

Markus EJ, Petit TL \& Le Boutillier JC 1987 Synaptic structural changes during development and aging. Brain Research $\mathbf{4 3 2}$ 239-248.

Menjo M, Murata Y, Fujii T, Nimura Y \& Seo H 1993 Effects of thyroid and glucocorticoid hormones on the level of messenger ribonucleic acid for iodothyronine type I $5^{\prime}$-deiodinase in rat primary hepatocytes grown as spheroids. Endocrinology 133 2984-2990.

Morreale de Escobar G, Calvo R, Obregón MJ \& Escobar del Rey F 1990 Contribution of maternal thyroxine to fetal thyroxine pools in normal rats near term. Endocrinology 126 2765-2767.

Morreale de Escobar G, Obregón MJ \& Escobar del Rey F 2004 Role of thyroid hormone during early brain development. European Journal of Endocrinology 151 U25-U37.

Pamenter RW \& Hedge GA 1980 Inhibition of thyrotropin secretion by physiological levels of corticosterone. Endocrinology 106 162-166.

Rostas JA, Kavanagh JM, Dodd PR, Heath JW \& Powis DA 1991 Mechanisms of synaptic plasticity. Changes in postsynaptic densities and glutamate receptors in chicken forebrain during maturation. Molecular Neurobiology 5 203-216.
Rubello D, Sonino N, Casara D, Girelli ME, Busnardo B \& Boscaro M 1992 Acute and chronic effects of high glucocorticoid levels on hypothalamic-pituitary-thyroid axis in man. Journal of Endocrinological Investigation 15 437-441.

Sedlácek J 1972 Development of the optic afferent system in chick embryos. Advances in Psychobiology 1 129-170.

Song S \& Oka T 2003 Regulation of type II deiodinase expression by EGF and glucocorticoid in HC11 mouse mammary epithelium. American Journal of Physiology - Endocrinology and Metabolism 284 E1119-E1124.

Van der Geyten S, Buys N, Sanders JP, Decuypere E, Visser TJ, Kühn ER \& Darras VM 1999 Acute pretranslational regulation of type III iodothyronine deiodinase by growth hormone and dexamethasone in chicken embryos. Molecular and Cellular Endocrinology 147 49-56.

Van der Geyten S, Segers I, Gereben B, Bartha T, Rudas P, Larsen PR, Kühn ER \& Darras VM 2001 Transcriptional regulation of iodothyronine deiodinases during embryonic development. Molecular and Cellular Endocrinology 183 1-9.

Wassen FWJS, Klootwijk W, Kaptein E, Duncker DJ, Visser TJ \& Kuiper GGJM 2004 Characteristics and thyroid state-dependent regulation of iodothyronine deiodinases in pigs. Endocrinology 145 4251-4263.

Westgren U, Ahrén B, Burger A, Ingemansson S \& Melander A 1977 Effects of dexamethasone, desoxycorticosterone, and ACTH on serum concentrations of thyroxine, 3,5, $3^{\prime}$-triiodothyronine and 3,3',5'-triiodothyronine. Acta Medica Scandinavica 202 89-92.

Yamaguchi S, Murata Y, Nagaya T, Hayashi Y, Ohmori S, Nimura Y \& Seo H 1999 Glucocorticoids increase retinoid-X receptor alpha $(\mathrm{RXR} \alpha)$ expression and enhance thyroid hormone action in primary cultured rat hepatocytes. Journal of Molecular Endocrinology 22 81-90.

Received in final form 1 February 2005 Accepted 16 February 2005 